\title{
Preparation of Silica Aerogel and Its Adsorption Performance to Organic Molecule
}

\author{
Hong-xin Shi, Jing-tao Cui, Hai-min Shen, and Hong-ke Wu \\ State Key Laboratory Breeding Base of Green Chemistry Synthesis Technology, Zhejiang University of Technology, \\ Hangzhou 310032, China
}

Correspondence should be addressed to Hong-xin Shi; shihxin@zjut.edu.cn

Received 11 September 2013; Accepted 6 January 2014; Published 20 February 2014

Academic Editor: Kuo Chuan Ho

Copyright (C) 2014 Hong-xin Shi et al. This is an open access article distributed under the Creative Commons Attribution License, which permits unrestricted use, distribution, and reproduction in any medium, provided the original work is properly cited.

Hydrophobic and lipophilic silica aerogel was prepared from water-glass by gelling, aging, silylation, and drying under atmospheric pressure and characterized by FT-IR and SEM. The effect of preparation process on aerogel density and the aerogel density on contact angle of water on it were investigated in detail. $\mathrm{pH} 6$ is most beneficial to shorten gelling time and to obtain the lowest density of silica aerogel. Increasing TEOS concentration of aging solution to $25 \mathrm{v} \%$ could decrease aerogel density to $0.093 \mathrm{~g} / \mathrm{cm}^{3}$. The silica aerogel exhibits good hydrophobicity even though its density is $0.30 \mathrm{~g} / \mathrm{cm}^{3}$. There are few changes in their adsorption capacities after 3 cycles of adsorption-desorption. The adsorption performance of the silica aerogel to organic solvent in water is different from in pure solvents. The critical surface tension $\left(\gamma_{C}\right)$ of the silica aerogel prepared here is about $30.8 \mathrm{mN} / \mathrm{m}$. If the surface tension of aqueous solvent solution $(\gamma)$ is greater than $\gamma_{C}$, it will wet the aerogel surface partially. If $\gamma \leq \gamma_{C}$, the solution will wet all aerogel surface and be adsorbed well. This work delivers us a method to adsorb solvents from their waste water by adjusting the surface tension of the waste water to lower than $\gamma_{C}$ of the adsorbent.

\section{Introduction}

Silica aerogel [1-4] is a nanostructured material with open foam-like structures having very low density (as low as $\left.3 \mathrm{~kg} / \mathrm{m}^{3}\right)$, high specific surface area $\left(700-1000 \mathrm{~m}^{2} / \mathrm{g}\right)$, and extremely high porosity (98\%-99\%) [5]. These features lead to unique properties due to excellent accessibility of the inner surface through open porous network. The most interesting feature of silica aerogel is the controllability of the surface polarity between hydrophobicity and hydrophilicity. Various applications such as thermal super insulation, catalyst support, microfilters, controlled release of drugs, and inertial confinement fusion targets have already been investigated and reported $[6,7]$. Because of their very high specific surface area and porosity as well as hydrophobicity, silica aerogel is an ideal adsorbent for organic compounds.

Rao et al. investigated the adsorption and desorption of organic liquids on silica aerogel and found that the aerogel could adsorb the organic liquids and oils by nearly 15 times of its own mass [8]. Wang et al. studied the equilibrium and kinetics of sorption of generic vegetable cooking oil, motor oil, and crude oil from the liquid phase and from an oil-inwater emulsion on two different particle-size hydrophobic silica aerogels and found that the aerogels had a very high capacity (up to $15.1 \mathrm{~g}$ oil $/ \mathrm{g}$ aerogel) and rate (uptake time of 25-1200 s) for adsorption of liquid oils; thus they regarded the aerogels as a very attractive adsorbent for oil spill cleanup [9]. Wang et al. investigated the adsorption of six volatile organic compounds in vapor, liquid, and aqueous solution on hydrophobic aerogels and found that the rate for adsorption are very different, with the uptake time in the order of about $100 \mathrm{~min}$ for vapor, $10 \mathrm{~min}$ for solution, and $10 \mathrm{~s}$ for liquid. The slowest rate of adsorption for vapor is due to the fact that the aerogel has an extremely low thermal conductivity [10]. Standeker et al. synthesized some silica aerogels and used them to adsorb toxic organic compounds from water. They found that the adsorption capacity of both hydrophobic silica aerogel adsorbents M9 and E6 exceeded the capacity of 
comparable granular activated carbon, for all toxic organic compounds tested in ranges of factors from 15 to 400 [3]. Štandeker et al. assessed the ability of modified silica aerogel with mercapto group to remove $\mathrm{Cu}$ (II) and $\mathrm{Hg}$ (II) from aqueous solutions using batch adsorption technique under equilibrium conditions. They found the adsorbent exhibited very high adsorption potential for $\mathrm{Cu}$ (II) and $\mathrm{Hg}$ (II) and more than $99.0 \%$ removal was achieved in the $\mathrm{pH}$ range of 4-6 [11].

The common preparation of silica aerogel includes supercritical drying and expensive raw materials like tetraethoxysilane which prohibit its commercialization. There are capillary forces in the gel pores which make the gel shrink and even lead to the gel collapse when aerogel is dried [12]. Supercritical drying process can avoid the shrinkage and the collapse of aerogel completely, but its high cost makes it difficult to prepare aerogel in large scale. Schwertfeger et al. used water-glass combined with silylation and drying of the lyogel under atmospheric pressure to produce durably hydrophobic aerogel [13]. Their new process makes the aerogel production become cost-effective and more commercial.

Silica aerogel shows a very high uptake capacity for pure organic compounds. It adsorbs about $14.3 \mathrm{~g}$ benzene, $13.6 \mathrm{~g}$ toluene, or $14.4 \mathrm{~g} p$-xylene per gram silica aerogel [10]. But its uptake capacity for organics from their aqueous solution cuts down sharply, for example, $87 \mathrm{mg}$ benzene, $223 \mathrm{mg}$ toluene, or $1064 \mathrm{mg}$-xylene per gram silica aerogel, respectively [10]. It is the hydrophobicity of silica aerogel that prohibits the aqueous solution of organic compounds entering into the interior pores of silica aerogel, and only external space but not internal space of the aerogel adsorbs the organic compounds. This is the main cause of the decreased uptake capacity of organic compounds on silica aerogels. In the present study, we used water-glass as precursor, combined with silylation and drying of the lyogel under atmospheric pressure to prepare silica aerogel. The performances to adsorb organic compounds from their aqueous solutions on the aerogel were studied. The uptake capacity of these adsorbent will increase greatly in the presence of penetrating agent.

\section{Experimental}

2.1. Preparation of the Silica Hydrogel. The silica hydrogels were prepared through Shen's process with water-glass as starting material [14, 15]. One $\mathrm{L}$ water-glass solution $\left(\mathrm{SiO}_{2}\right.$ content $\left.8 \mathrm{wt} \%, n\left(\mathrm{Na}_{2} \mathrm{O}\right): n\left(\mathrm{SiO}_{2}\right)=1: 3.1\right)$ was filtrated to remove solid impurities. $81 \mathrm{~g}$ water-glass solution was dropped into $4.5 \mathrm{~g} \mathrm{35 \%}$ hydrochloric acid with agitation at ambient temperature. After dropping, the mixture was continued agitation for $7 \mathrm{~h}$ to hydrolyze the water-glass. Then, some aqueous ammonia solution was added to adjust the $\mathrm{pH}$ value of the mixture. The hydrogel obtained was aged in distilled water for $2 \mathrm{~h}$ and in anhydrous alcohol for several hours at ambient temperature, respectively.
2.2. Silylation and Drying of the Silica Hydrogels. For the silylation, $5 \mathrm{~g}$ of the aged hydrogel sticks was placed together with $20 \mathrm{~g}$ hexamethyldisiloxane (HMDSO), $15 \mathrm{~g}$ trimethylchlorosilane (TMCS), and $50 \mathrm{~mL}$ hexane in a beaker at ambient temperature for $24 \mathrm{~h}$. The resulted silylated lyogel sticks were dried at ambient temperature for $2 \mathrm{~h}$, then elevated temperature at $1^{\circ} \mathrm{C} / \mathrm{min}$ to $60^{\circ} \mathrm{C}$, and stayed at $60^{\circ} \mathrm{C}$ for $2 \mathrm{~h}$. After cooling to ambient temperature, the silica aerogel was obtained.

2.3. Characterization of the Silica Aerogels. The microstructure of the silica aerogel was observed by Hitachi S- 4700 field emission scanning electron microscope (Hitachi). Specific surface and pore radius were measured by SP 1900 Physisorption Analyzers. Hydrophobicity was presented as water contact angle on the aerogel which was measured by OCA-20 optical contact angle measuring system (Dataphysics). Silylation efficiency was measured by NEXUS Fourier transform infrared spectroscopy (Thermo Nicolet). The bulk density $\left(\rho_{b}\right)$ of the aerogel was measured using a known volume of the aerogel and its weight was measured with a microbalance, $10^{-5} \mathrm{~g}$ accuracy.

2.4. Adsorption Capacity Determination. The aerogel sample was kept in an organic solvent until it was completely wetted by the liquid. A conventional batch equilibration procedure was used as isotherm testing [16]. To achieve accurate results, the adsorption measurements were accomplished under equilibrium conditions.

\section{Results and Discussion}

Using low-cost industrial water-glass as silicon source to produce silicon aerogel, complete ionic exchange and water washing are necessary steps. But the process using water-glass with the two steps of acid-base catalysts $\left(\mathrm{HNO}_{3}-\mathrm{NaOH}\right)$, without ionic exchange, and possessing surface modification under atmospheric condition to produce nanoporous silica aerogels was reported [14]. We used hydrochloric acid and aqueous ammonia solution $\left(\mathrm{HCl}-\mathrm{NH}_{4} \mathrm{OH}\right)$ to substitute $\mathrm{HNO}_{3}-\mathrm{NaOH}$. The hydrolyzation is presented as the reactions (1) (3). Reactions (2) and (3) are the same as reaction (4):

$$
\begin{gathered}
\mathrm{Na}_{2} \mathrm{O}+2 \mathrm{HCl} \longrightarrow 2 \mathrm{NaCl}+\mathrm{H}_{2} \mathrm{O} \\
\mathrm{SiO}_{2}+6 \mathrm{HCl} \longrightarrow \mathrm{H}_{2}\left[\mathrm{SiCl}_{6}\right]+2 \mathrm{H}_{2} \mathrm{O} \\
\mathrm{H}_{2}\left[\mathrm{SiCl}_{6}\right]+4 \mathrm{H}_{2} \mathrm{O} \longrightarrow \mathrm{H}_{4} \mathrm{SiO}_{4}+6 \mathrm{HCl} \\
(2)+(3) \longrightarrow \mathrm{SiO}_{2}+2 \mathrm{H}_{2} \mathrm{O}=\mathrm{H}_{4} \mathrm{SiO}_{4}
\end{gathered}
$$

After neutralizing with $\mathrm{NH}_{4} \mathrm{OH}$, the mixture gelled and polycondensed to three-dimension molecules (5). 


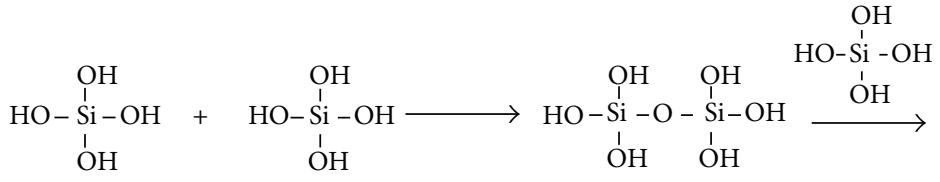

$\mathrm{OH}$<smiles>O[Si](O)(O)O[Si](O)(O)O[Si](O)(O)O</smiles>

$\mathrm{HO}-\mathrm{Si}-\mathrm{OH}$

$\mathrm{OH}$


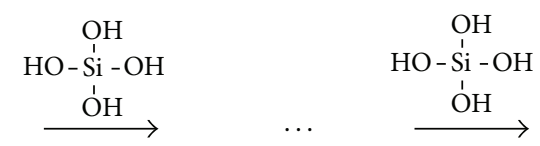

Three dimension linked molecules

The relation of gelling time to the $\mathrm{pH}$ value of the mixture was shown in Figure 1. When the mixture was acidic, for example, $\mathrm{pH} 4$, hydrolization was fast, and the polycondensation of the orthosilicic acid $\left(\mathrm{H}_{4} \mathrm{SiO}_{4}\right)$ was slow, the mixture gelled slowly and took about $260 \mathrm{~min}$. The gelling time declined sharply with increased $\mathrm{pH}$ value and was $20 \mathrm{~min}$ at $\mathrm{pH} 6$. When the $\mathrm{pH}$ value increased from $\mathrm{pH} 6$ to $\mathrm{pH}$, the gelling time declined very slowly, but white floccule appeared at $\mathrm{pH} 7$ and white deposit occurred quickly at $\mathrm{pH}$ 8. The polycondensation rate increased with the increase of the $\mathrm{pH}$ value of the mixture, and when $\mathrm{pH}$ value is greater than $6, \mathrm{H}_{4} \mathrm{SiO}_{4}$ condenses so quickly that it was easy to form gel particles, gathered to form white floccules $(\mathrm{pH}$ 7) and even a dense white deposit ( $\mathrm{pH}$ 8). So, $\mathrm{pH} 6$ is most proper for gelling. Good aerogel generally has very high porosity which produces its low density and high specific surface area. Shen has found that two steps of $\mathrm{HNO}_{3}-\mathrm{NaOH}$ catalysts with water-glass could result in lower aerogel density $\left(0.068 \sim 0.096 \mathrm{~g} / \mathrm{cm}^{3}\right)$ than that of quick step of $\mathrm{HF}\left(0.327 \sim 0.354 \mathrm{~g} / \mathrm{cm}^{3}\right)$. We found that adding $\mathrm{NH}_{4} \mathrm{OH}$ to the mixture could influence the aerogel density obtained. The effect of the $\mathrm{pH}$ value of the mixture on the aerogel density was shown in Figure 2. Figure 2 shows that gelling at $\mathrm{pH} 6$ could prepare aerogel with the smallest density. Elevating or decreasing the $\mathrm{pH}$ value of the mixture made the aerogel density increase. It is clear that $\mathrm{pH} 6$ is the best $\mathrm{pH}$ value in gelling. The hydrolization rate may be equal to the polycondensation rate at $\mathrm{pH}$ 6; the aerogel grew properly in three dimensions and formed some internal pores which made the aerogel density decline. If the $\mathrm{pH}$ value was smaller than 6 , the hydrolization rate may be greater than the polycondensation rate; many aerogel particles appeared and grew at the same time which made aerogel particle become smaller and made internal pores reduce, so that the aerogel density increased. If the $\mathrm{pH}$ value was great than 6 , for example, $\mathrm{pH} 8$, the hydrolization rate may be smaller than the polycondensation rate, $\mathrm{H}_{4} \mathrm{SiO}_{4}$ polycondensed very quickly as soon as it produced from hydrolyzation, precipitation but not aerogel growth took place, and few pores formed so that the aerogel density also increased.

Aging of hydrogel is very important operation for preparing silica aerogel. The polycondensation inside hydrogel does not finish completely without aging; then the hydrogel network will be not strong enough to endure the capillary force added by the surface tension of solvent during drying stage, which makes the aerogel shrink and dilapidate. Aging of hydrogel is a necessary step for aerogel to avoid shrinkage and dilapidation. In aging operation, hydrogel, were dipped into $0 \%, 5 \%, 15 \%, 25 \%, 35 \%$, and $40 \%$ tetraethoxysilane $\left(C_{\text {TEOS }} \mathrm{v} \%\right)$ solution in ethanol, respectively. The effect of $C_{\text {TEOS }} \mathrm{v} \%$ of aging solution on the aerogel density was shown in Figure 3.

When pure ethanol was used, $C_{\mathrm{TEOS}}=0 \mathrm{v} \%$, the density was $0.15 \mathrm{~g} / \mathrm{cm}^{3}$; adding TEOS gradually, the density declined firstly and then increased; when $C_{\mathrm{TEOS}}=25 \mathrm{v} \%$, the density reached the smallest value, $0.093 \mathrm{~g} / \mathrm{cm}^{3}$; when $C_{\text {TEOS }}>25 \mathrm{v} \%$, the density turned to increase. This is because there was water in hydrogel which made TEOS hydrolyze to $\equiv \mathrm{Si}-\mathrm{OH},=\mathrm{Si}(\mathrm{OH})_{2}$, and $-\mathrm{Si}(\mathrm{OH})_{3}$; they reacted with the hydroxy groups of hydrogel to strengthen hydrogel network, so that to delimit the aerogel shrinkage during drying. Before aging, there were many interpores full of water in the hydrogel. During aging, the water in the pores could be substituted by ethanol. This substitution should be finished enough so that the aerogel could avoid shrinkage and collapse; then smaller density of aerogel could be obtained. When $C_{\text {TEOS }}$ was lower, the water was substituted completely. When $C_{\text {TEOS }}$ was higher, or $C_{\text {ethanol }}$ was lower, the water could not be substituted completely. The higher the $C_{\mathrm{TEOS}}$, the more the water remained in the pores and the more shrinkage and collapse of aerogel, then the greater the aerogel density.

The silica aerogel prepared is Cambridge blue solid with BET surface area of $838.6 \mathrm{~m}^{2} / \mathrm{g}$, pore volume of $1.072 \mathrm{~cm}^{3} / \mathrm{g}$, and average pore width of $5.11 \mathrm{~nm}$. SEM image of the silica aerogel was shown in Figure 4 . It is very clear that the silica aerogel is multiporous nanomaterial with concatenate 


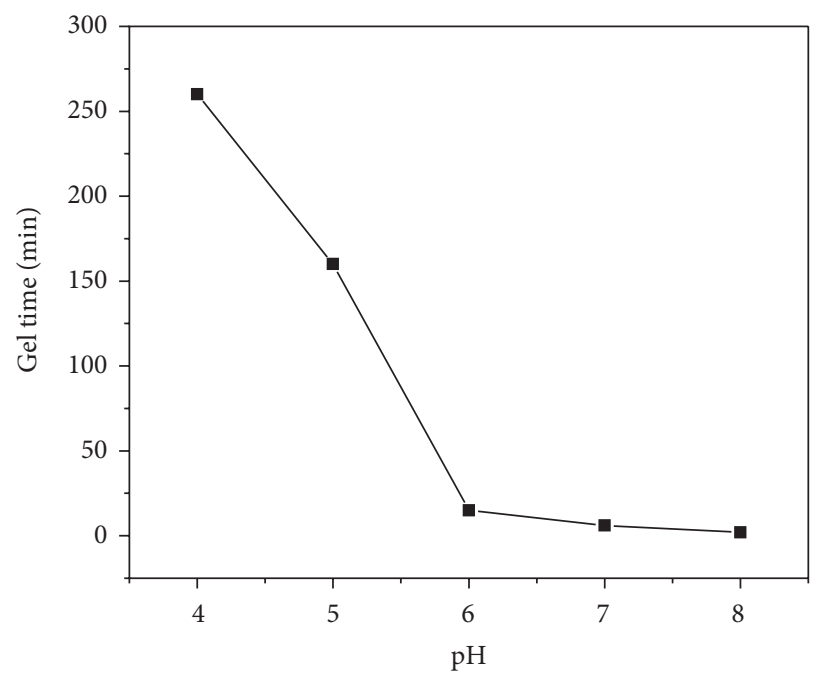

FIGURE 1: The relation of gelling time to the $\mathrm{pH}$ value of the mixture.



Figure 2: The relation of aerogel density to the $\mathrm{pH}$ value of the mixture.

network structure. Because the external and internal surfaces of the aerogel were treated with hexamethyldisiloxane (HMDSO) and trimethylchlorosilane (TMCS), it exhibited hydrophobicity. The image of water on the silica aerogel prepared was shown in Figure 5. The water contact angle on the aerogel was about $138^{\circ}$.

The water contact angle on aerogel is related to the preparation process containing silicon source, gelling, aging, silylation, and drying; all of that can influence the aerogel density, which determines the water contact angle on the aerogel and its hydrophobicity. We selected some silica aerogels with different densities ranged from $0.093 \mathrm{~g} / \mathrm{cm}^{3}$ to $0.30 \mathrm{~g} / \mathrm{cm}^{3}$ and measured their water contact angles which ranging from $138^{\circ}$ to $110^{\circ}$. The relation of the water contact angle to aerogel density was shown in Figure 6. It is very clear that the water contact angle on the silica aerogel declines

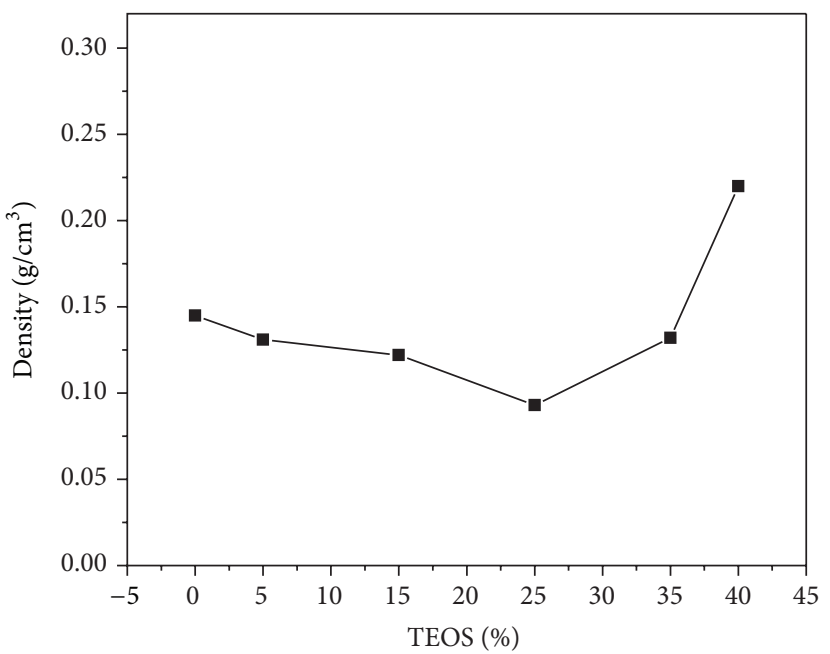

FIGURE 3: The relation of aerogel density to the TEOS concentration in aging solution.

gradually with the increase of its density. The lower the aerogel density, the greater the water contact angle. The silica aerogel presents good hydrophobicity even though its density is $0.30 \mathrm{~g} / \mathrm{cm}^{3}$. This result tells us that controlling silica aerogel density can adjust its hydrophobicity.

Hydrophobic silica aerogel is lipophilic and can adsorb organic compounds. One g powdery active carbon, silica gel, and silica aerogel $\left(0.084 \mathrm{~g} / \mathrm{cm}^{3}\right)$ prepared were added into pure toluene, xylene, chlorobenzene, DMSO, and $\mathrm{MeOH}$ at ambient temperature for $1 \mathrm{~h}$, respectively. After filtration in vacuum, the wet solid adsorbents were weighted and the adsorption capacities of each adsorbents were calculated, which were shown in Figure 7. For adsorbates, the adsorption capacity order is silica aerogel $\gg$ silica gel $>$ active carbon except for $\mathrm{MeOH}$. Active carbon is a common adsorbent for organic adsorbates; its adsorption capacity is smaller than 


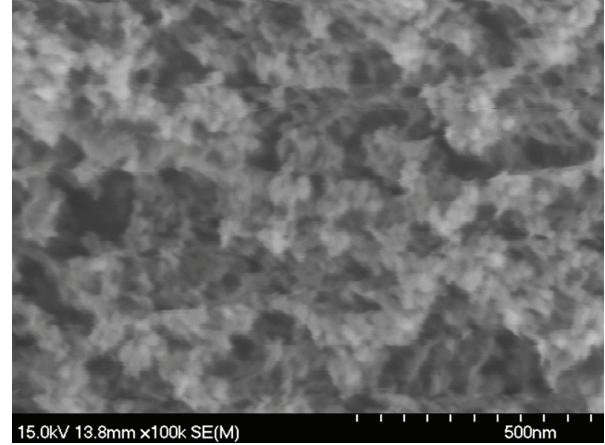

FIgURE 4: SEM micrograph of silica aerogel.

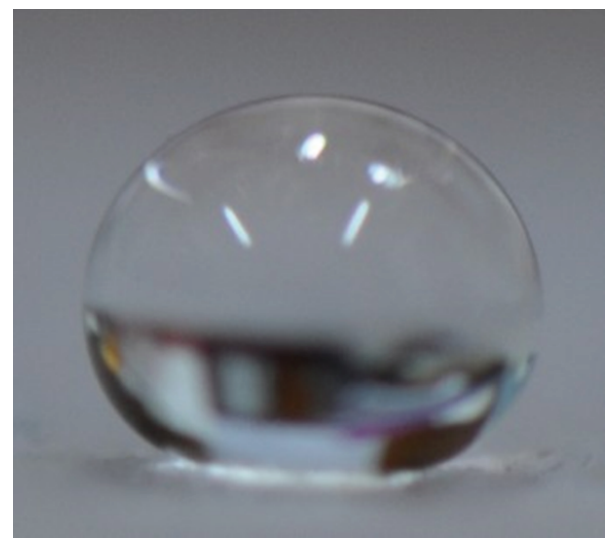

FIGURE 5: Image of water on the silica aerogel.

$1 \mathrm{~g} / \mathrm{g}$ for organic compounds tested. But the corresponding adsorption capacity of silica aerogel is equal to or greater than $7 \mathrm{~g} / \mathrm{g}$. The aerogel can especially adsorb about 10 times of chlorobenzene compared to 0.4 time for active carbon. Silica aerogel exhibits excellent adsorption performance.

After adsorption, organic adsorbates were desorbed from silica aerogel at ambient temperature. Elevated temperature will quicken desorption. For example, it takes about $220 \mathrm{~min}$ (at $25^{\circ} \mathrm{C}$ ) and $10 \mathrm{~min}\left(\right.$ at $100^{\circ} \mathrm{C}$ ) for toluene desorption, respectively. The images of silica aerogel in different states of adsorbing and desorbing toluene were shown in Figure 8. After absorbing toluene, the volume of aerogel became a little bigger and its color looked gloomy. After desorption, the appearance of aerogel seemed to return to its original state.

After desorption, the silica aerogel was applied to adsorb organic compounds again and their adsorption capacities were listed in Table 1. There are few changes in their adsorption capacities among the first, the second, and the third cycles.

Various aqueous solutions of THF, DMF, acetone, $\mathrm{CH}_{3} \mathrm{CN}$, ethanol, $\mathrm{AcOH}$, and $\mathrm{MeOH}$ were prepared. $0.05 \mathrm{~g}$ silica aerogel was added into $20 \mathrm{~mL}$ solutions at ambient temperature for sufficient time, respectively, and the adsorption capacities were calculated. The capacities of silica aerogel to adsorb solvent from their aqueous solution in different volume concentrations $\left(C_{\text {Solvent }}\right)$ were recorded in Figure 9.

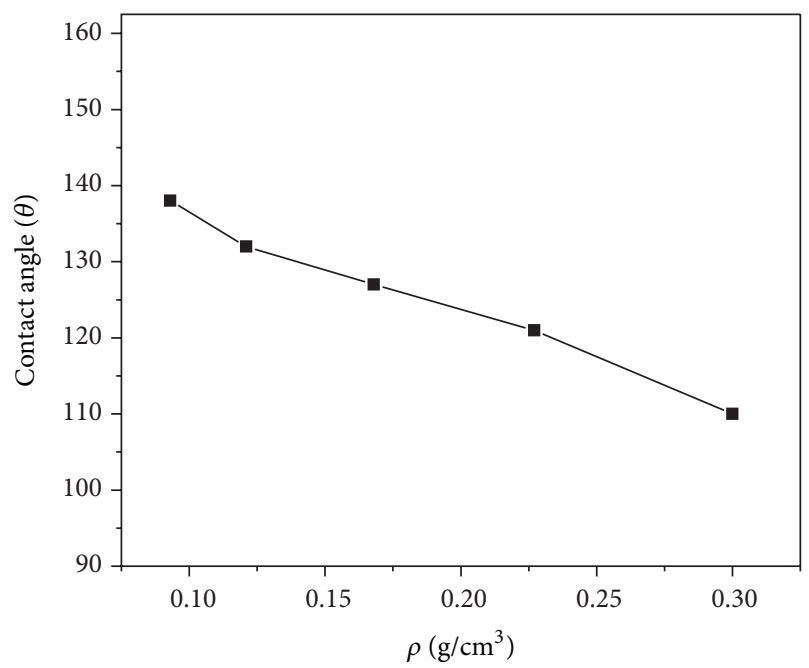

FIGURE 6: Water contact angle versus aerogel density.

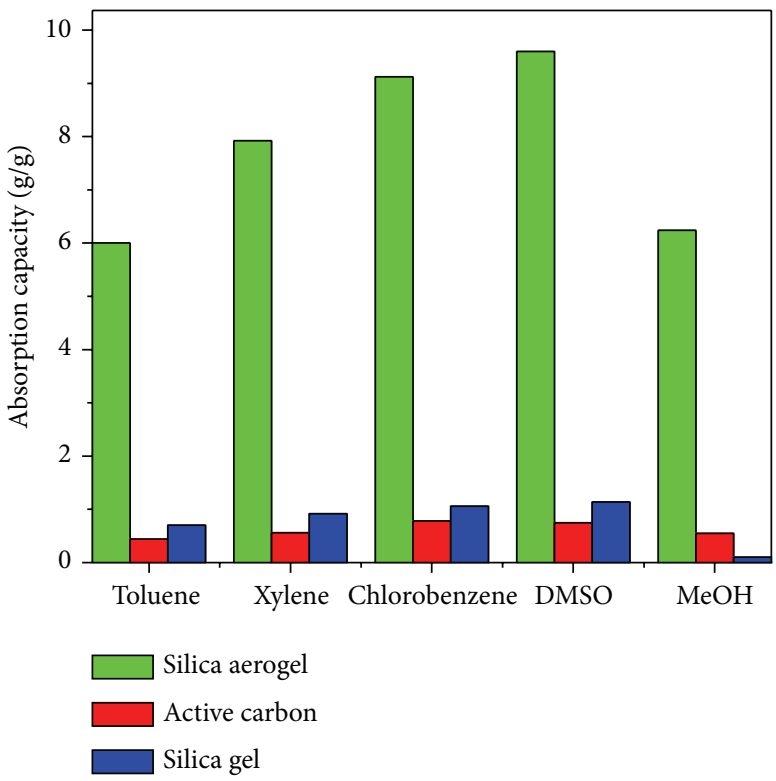

Figure 7: Adsorption capacities of various adsorbents.

It is shown that when $C_{\text {Solvent }}$ is lower than $30 \mathrm{v} \%$, the adsorption capacities are similar and smaller than $1 \mathrm{~g} / \mathrm{g}$. Increasing $C_{\text {Solvent }}$, especially from $30 \mathrm{v} \%$ to $50 \mathrm{v} \%$, the adsorption capacities increase sharply. If $C_{\text {Solvent }}$ continues to increase, the adsorption capacities continue to increase slowly. The performances of aerogel in adsorbing pure solvents and aqueous solvent solutions are very different. In adsorption equilibrium, the adsorbing capacities in aqueous solvent solutions are very lower than those of corresponding pure solvents. For example, the capacity to adsorb $30 \mathrm{v} \%$ ethanol solution is about $0.85 \mathrm{~g} / \mathrm{g}$, but $7.00 \mathrm{~g} / \mathrm{g}$ for pure ethanol. The adsorbing performance of aerogel to DMF solution is very interesting. When $C_{\mathrm{DMF}}<75 \mathrm{v} \%$, little adsorption takes place, but when $C_{\mathrm{DMF}}$ increases a little, the adsorption capacity increases sharply. When $C_{\mathrm{DMF}}=80 \mathrm{v} \%$, the adsorption 


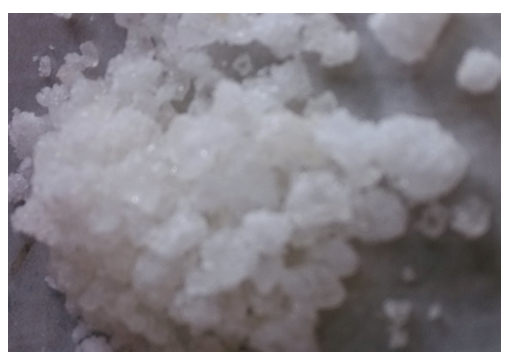

Before adsorption

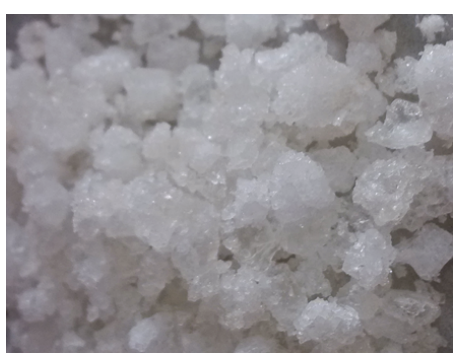

After adsorption

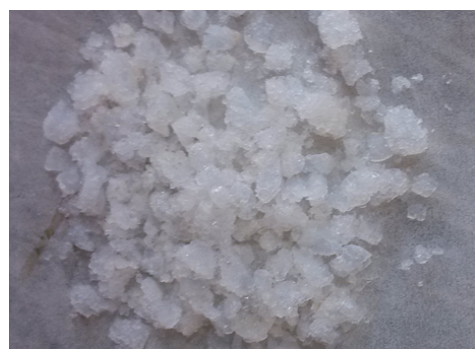

After desorption

FIGURE 8: Images of aerogel adsorbing and desorbing toluene.

TABLE 1: The adsorption capacities of silica aerogel.

\begin{tabular}{lcccc}
\hline No & Adsorbate & \multicolumn{2}{c}{ Adsorption capacities $(\mathrm{g} / \mathrm{g})$} \\
Second cycle & First cycle & 10.06 & 10.01 \\
\hline 1 & Chlorobenzene & 10.12 & 9.51 & 9.44 \\
2 & DMSO & 9.60 & 8.89 & 8.82 \\
3 & Xylene & 8.92 & 7.19 & 7.11 \\
4 & Methanol & 7.24 & 6.94 & 6.95 \\
5 & Toluene & 7.00 & & \\
\hline
\end{tabular}

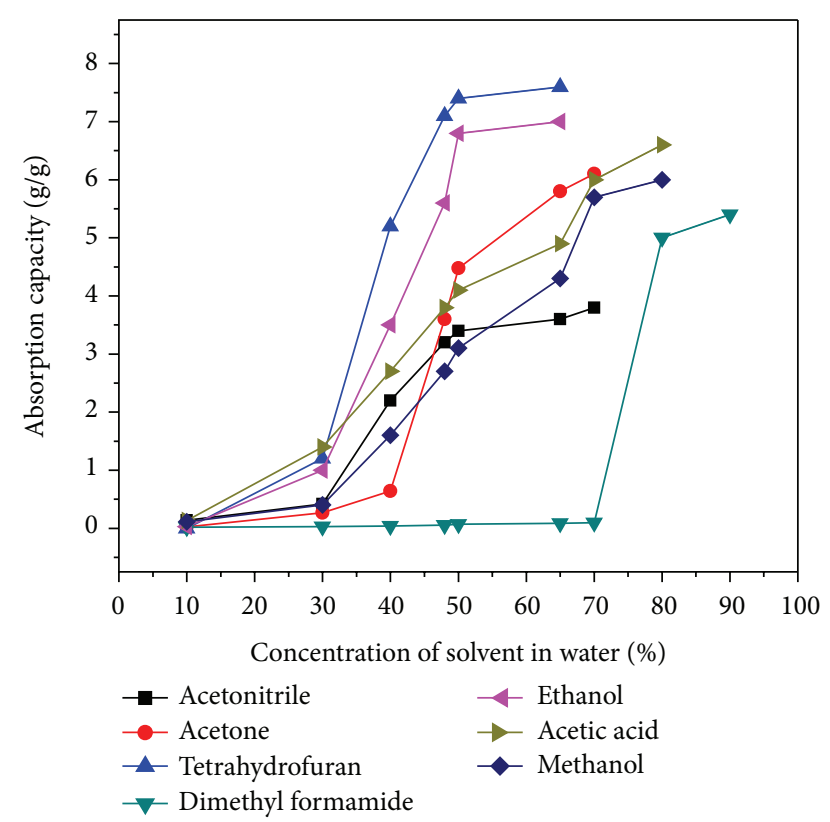

FIGURE 9: Capacities of silica aerogel adsorbing solvents from their aqueous solution.

capacity reaches to $5.0 \mathrm{~g} / \mathrm{g}$. The differences of adsorption capacities of aerogel between pure solvents and aqueous solvent solutions may be caused by surface hydrophobicity and lipophilicity of silica aerogel.

Figure 10 presents the balance of forces at the solid-vapor, solid-liquid, and liquid-vapor interface. If the contact angle is above $90^{\circ}$, there is no spreading of the liquid and the aerogel is said to be impervious. When the contact angle is less than $90^{\circ}$, the liquid spreads on the aerogel surface and when the

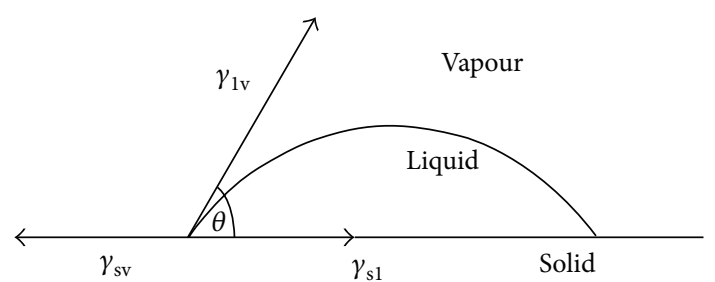

FIGURE 10: Balance of forces at the contact line solid-liquid-vapor system.

liquid is completely adsorbed by the aerogel, the contact angle is equal to zero. The imper-viousness of the aerogels against solvents in water observed in various concentrations was researched by the contact angle measurements. Table 2 shows the contact angle $(\theta)$ of aqueous solution with different percentage of solvents $\left(C_{\text {Solvent }}, \mathrm{v} \%\right)$. It is very clear from Table 2 that, with the increase of $C_{\text {Solvent, }}$ the contact angle decreases. The aerogel is impervious against the solvents in water, the concentrations of which are up to $37 \mathrm{v} \%$ (THF), $48 \mathrm{v} \%$ (acetone), $34 \mathrm{v} \%\left(\mathrm{CH}_{3} \mathrm{CN}\right), 74 \mathrm{v} \%$ (DMF), $35 \mathrm{v} \%$ (ethanol), $26 \mathrm{v} \%$ (acetic acid), and 39 v\% (methanol), respectively.

The mass of the organic liquid adsorbed by aerogel depends upon the surface tension $(\gamma)$ of the corresponding liquid. From Young's equation [17],

$$
\gamma_{\mathrm{sv}}=\gamma_{\mathrm{sl}}+\gamma_{\mathrm{lv}} \cos \theta
$$

where $\gamma_{\mathrm{sv}}, \gamma_{\mathrm{sl}}$, and $\gamma_{\mathrm{lv}}$ are solid-vapor, solid-liquid, and liquidvapor interfacial energies, respectively (Figure 10). If the material has a low energy $\operatorname{surface}\left(\gamma_{\mathrm{sv}}<\gamma_{\mathrm{sl}}\right)$, the contact angle $(\theta)$ will be $>90^{\circ}$ and the liquid cannot spread on the surface but remain in the form of a drop. This phenomenon 
TABLE 2: Contact angle measurements for silica aerogel with different solvents in water.

\begin{tabular}{|c|c|c|}
\hline Solvent & $C_{\text {Solvent }}(\mathrm{v} \%)$ & Contact angle $\left({ }^{\circ}\right)$ \\
\hline \multirow{6}{*}{ THF } & 0 & 153 \\
\hline & 10 & 150 \\
\hline & 30 & 137 \\
\hline & 37 & 90 \\
\hline & 40 & 82 \\
\hline & 48 & Adsorption \\
\hline \multirow{6}{*}{ Acetone } & 10 & 147 \\
\hline & 30 & 145 \\
\hline & 40 & 137 \\
\hline & 48 & 90 \\
\hline & 50 & 85 \\
\hline & 65 & Adsorption \\
\hline \multirow{7}{*}{$\mathrm{CH}_{3} \mathrm{OH}$} & 10 & 147 \\
\hline & 30 & 126 \\
\hline & 39 & 90 \\
\hline & 40 & 86 \\
\hline & 50 & 69 \\
\hline & 70 & 34 \\
\hline & 73 & Adsorption \\
\hline \multirow{5}{*}{$\mathrm{CH}_{3} \mathrm{CN}$} & 10 & 150 \\
\hline & 30 & 130 \\
\hline & 34 & 90 \\
\hline & 40 & 69 \\
\hline & 50 & Adsorption \\
\hline \multirow{6}{*}{$\mathrm{C}_{2} \mathrm{H}_{5} \mathrm{OH}$} & 10 & 148 \\
\hline & 30 & 110 \\
\hline & 35 & 90 \\
\hline & 40 & 70 \\
\hline & 50 & 40 \\
\hline & 53 & Adsorption \\
\hline \multirow{6}{*}{$\mathrm{DMF}$} & 10 & 148 \\
\hline & 50 & 141 \\
\hline & 70 & 138 \\
\hline & 74 & 90 \\
\hline & 75 & 80 \\
\hline & 90 & Adsorption \\
\hline \multirow{7}{*}{$\mathrm{CH}_{3} \mathrm{COOH}$} & 10 & 143 \\
\hline & 26 & 90 \\
\hline & 30 & 82 \\
\hline & 40 & 63 \\
\hline & 50 & 41 \\
\hline & 70 & 21 \\
\hline & 78 & Adsorption \\
\hline
\end{tabular}

is observed when $C_{\text {Solvent }}$ is low, for example, $10 \mathrm{v} \%$. If the material has a high energy surface $\left(\gamma_{\mathrm{sv}}>\gamma_{\mathrm{sl}}\right)$, the contact angle $(\theta)$ will be less than $90^{\circ}$ and the liquid can spread on the surface. For example, when $C_{\text {Methanol }}=70 \mathrm{v} \%$, the aqueous methanol solution spreads on the aerogel. If the material has a very high energy surface $\left(\gamma_{\mathrm{sv}} \gg \gamma_{\mathrm{sl}}\right)$, the contact angle $(\theta)$ will
TABLE 3: The lowest concentration of solvents solution in which $\theta=$ 0 and their surface tensions.

\begin{tabular}{lcccc}
\hline Solvent & Ethanol & Methanol & THF & Acetone \\
\hline$C(\mathrm{v} \%)$ & 53 & 73 & 48 & 65 \\
$\gamma(\mathrm{mN} / \mathrm{m})$ & 29.6 & 31.0 & 31.9 & 30.9 \\
\hline
\end{tabular}

be zero and the liquid is fully adsorbed by the material. For example, when $C_{\text {Methanol }}=73 \mathrm{v} \%$, methanol was adsorbed completely by the aerogel.

Table 3 shows the lowest concentrations of ethanol, methanol, THF, and acetone in water in which the solvent solutions can be adsorbed by the silica aerogel (i.e., $\theta=0$ ). We measured the surface tensions of these aqueous solutions and listed these results in Table 3 . From the data, we found that the average surface tension is about $30.9 \mathrm{mN} / \mathrm{m}$ which equals the critical surface tension $\left(\gamma_{C}\right)$ of the silica aerogel according to Zisman's rule [18]. If the surface tension of aqueous solvent solution $\gamma>\gamma_{C}$, the solution will wet the aerogel surface partially. If $\gamma \leq \gamma_{C}$, the solution will wet all of the aerogel surface. If $\gamma \gg \gamma_{C}$, the solution hardly enters inside aerogel and wets few aerogel surface, and the contact angel of the solution drop is greater than $90^{\circ}$, so aerogel adsorbs little solvent from the solvent solution in water. We prepared $20 \mathrm{v} \%$ solvent solutions in water, using penetrating agent A (delivered by Taizu New Materials Co., Ltd) to adjust the surface tensions of these solutions and measured the capacities of aerogel adsorbing the solvents in water before and after adjustment, respectively. The results were listed in Table 4 and show that the surface tensions of aqueous $20 \mathrm{v} \%$ solvent solutions are greater than $\gamma_{C}$, so their adsorption capacities are very small; once adding penetrating agent A in the solvent solutions, the surface tensions decline sharply to much smaller than $\gamma_{C}$, and the adsorption capacities are increased sharply. This deliver us a process to adsorb solvents from their waste water by adjusting the surface tension of the waste water to much lower than $\gamma_{C}$ of the adsorbent. This will be very useful and practical to deal with the waste water containing some organic compounds.

\section{Conclusion}

Hydrophobic and lipophilic silica aerogel was prepared from water-glass by gelling, aging, silylation and drying at atmospheric pressure. The $\mathrm{pH}$ value influence the gelling time of water-glass mixture. $\mathrm{pH} 6$ is the best value to shorten gelling time and to obtain the lowest density of silica aerogel. Increasing TEOS concentration of aging solution to $25 \mathrm{v} \%$ could decrease aerogel density to $0.093 \mathrm{~g} / \mathrm{cm}^{3}$. The preparation process will influence the aerogel density which determins the water contact angle on the aerogel, that is, its hydrophobisity. The water contact angle on the silica aerogel declines gradually with the increase of its density. The silica aerogel exhibits good hydrophobicity even though its density is $0.30 \mathrm{~g} / \mathrm{cm}^{3}$. The adsorption capacities of silica aerogel are equal to or greater than $7 \mathrm{~g}$ organics tested/g adsorbent. There are few changes in their adsorption capacities after 3 cycles of adsorption-desorption. The performances of aerogel 
TABLE 4: The adsorption capacities of $20 \mathrm{v} \%$ solvent solutions in water in different surface tensions.

\begin{tabular}{lcccc}
\hline Solutions & \multicolumn{2}{c}{$20 \mathrm{v} \%$ solvent } & \multicolumn{2}{c}{$20 \mathrm{v} \%$ solvent-6 g/L penetrating agent } \\
Adsorption capacity $(\mathrm{g} / \mathrm{g})$
\end{tabular}

adsorbing to solvent solutions in water are different from those in the pure solvents. When $C_{\text {Solvent }}$ is lower than $30 \mathrm{v} \%$, the adsorption capacities are similar and smaller than $1 \mathrm{~g}$ solvent/g adsorbent. The critical surface tension $\left(\gamma_{C}\right)$ of the silica aerogel prepared is about $30.8 \mathrm{mN} / \mathrm{m}$. If the surface tension of aqueous solvent solution $(\gamma)$ is greater than $\gamma_{C}$, it will wet the aerogel surface partially. If $\gamma \leq \gamma_{C}$, the solution will wet all the aerogel surface. Adjusting surface tension of the solvent solution in water to much smaller than $\gamma_{C}$ of aerogel, the aerogel will adsorb solvent efficiently from its aqueous solution.

\section{Conflict of Interests}

The authors declare that there is no conflict of interests regarding the publication of this paper.

\section{Acknowledgment}

This work is financially supported by the Department of Science and Technology of Zhejiang Province (Grant no. 2011R09002-10).

\section{References}

[1] A. V. Rao, M. M. Kulkarni, D. P. Amalnerkar, and T. Seth, "Superhydrophobic silica aerogels based on methyltrimethoxysilane precursor," Journal of Non-Crystalline Solids, vol. 330, no. 1-3, pp. 187-195, 2003.

[2] L. W. Hrubesh, P. R. Coronado, and J. H. Satcher Jr., "Solvent removal from water with hydrophobic aerogels," Journal of NonCrystalline Solids, vol. 285, no. 1-3, pp. 328-332, 2001.

[3] S. Štandeker, Z. Novak, and Ž. Knez, "Adsorption of toxic organic compounds from water with hydrophobic silica aerogels," Journal of Colloid and Interface Science, vol. 310, no. 2, pp. 362-368, 2007.

[4] A. P. Rao, A. V. Rao, and G. M. Pajonk, "Hydrophobic and physical properties of the ambient pressure dried silica aerogels with sodium silicate precursor using various surface modification agents," Applied Surface Science, vol. 253, no. 14, pp. 6032-6040, 2007.

[5] G. F. Han, Z. W. Wu, X. D. Shen et al., "Preparations and adsorption properties of hydrophobic silica aerogels," Journal of Nanjing University of Technology, vol. 32, no. 1, pp. 59-62, 2010.

[6] L. W. Hrubesh, "Aerogel applications," Journal of NonCrystalline Solids, vol. 225, no. 1-3, pp. 335-342, 1998.
[7] J. Fricke and T. Tillotson, "Aerogels: production, characterization, and applications," Thin Solid Films, vol. 297, no. 1-2, pp. 212-223, 1997.

[8] A. V. Rao, N. D. Hegde, and H. Hirashima, "Absorption and desorption of organic liquids in elastic superhydrophobic silica aerogels," Journal of Colloid and Interface Science, vol. 305, no. 1, pp. 124-132, 2007.

[9] D. Wang, E. McLaughlin, R. Pfeffer, and Y. S. Lin, "Adsorption of oils from pure liquid and oil-water emulsion on hydrophobic silicaaerogels," Separation and Purification Technology, vol. 99, pp. 28-35, 2012.

[10] D. Wang, E. McLaughlin, R. Pfeffer, and Y. S. Lin, "Adsorption of organic compounds in vapor, liquid, and aqueous solution phases on hydrophobic aerogels," Industrial and Engineering Chemistry Research, vol. 50, no. 21, pp. 12177-12185, 2011.

[11] S. Štandeker, A. Veronovski, Z. Novak, and Ž. Knez, "Silica aerogels modified with mercapto functional groups used for $\mathrm{Cu}$ (II) and $\mathrm{Hg}(\mathrm{II})$ removal from aqueous solutions," Desalination, vol. 269, no. 1-3, pp. 223-230, 2011.

[12] C. J. Brinker and G. W. Scherer, Eds., Sol-Gel Science, Academic Press, New York, NY, USA, 1990.

[13] F. Schwertfeger, D. Frank, and M. Schmidt, "Hydrophobic waterglass based aerogels without solvent exchange or supercritical drying," Journal of Non-Crystalline Solids, vol. 225, no. 1-3, pp. 24-29, 1998.

[14] G. Liu, B. Zhou, X. Ni, J. Shen, A. Du, and G. Zu, "Preparation of super-hydrophobic $\mathrm{SiO}_{2}$ aerogel monoliths from sodium silicate," Journal of the Chinese Ceramic Society, vol. 40, no. 1, pp. 160-164, 2012.

[15] J. Shen, J.-C. Wang, X.-Y. Ni, B. Wang, X.-D. Wang, and Z.-H. Zhang, "Preparation of silica aerogels with non-ionic exchange water glass," Journal of Functional Materials, vol. 40, no. 1, pp. 149-152, 2009.

[16] S. Cui, X. Liu, Y. Liu et al., "Adsorption properties of nitrobenzene in wastewater with silica aerogels," Science China Technological Sciences, vol. 53, no. 9, pp. 2367-2371, 2010.

[17] A. W. Adamson, Physical Chemistry of Surfaces, John Wiley, New York, NY, USA, 1982.

[18] P. G. Gennes, F. B. Wyart, and D. Quere, Capillarity and Wetting Phenomena, Springer, Berlin, Germany, 2004. 

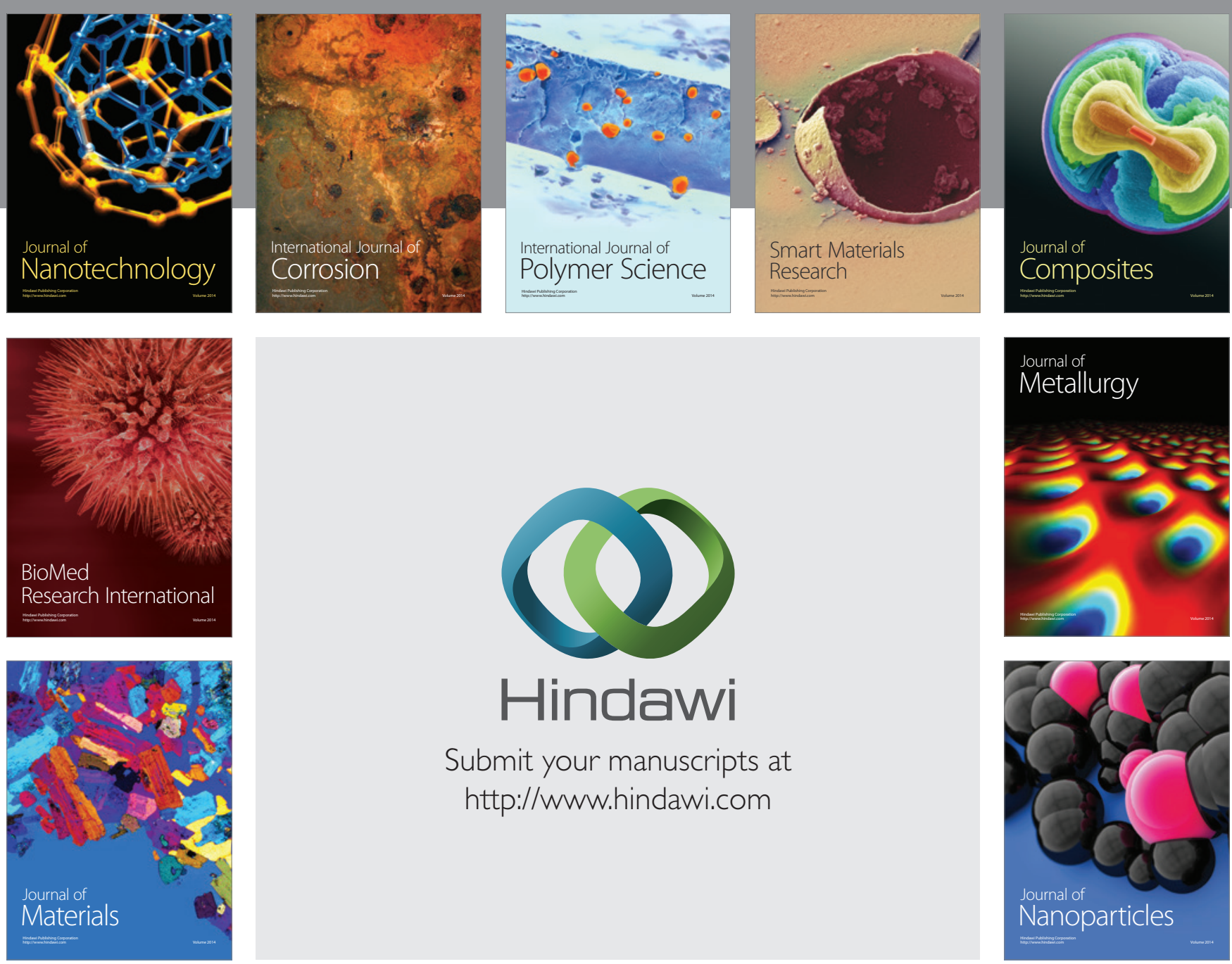

Submit your manuscripts at http://www.hindawi.com
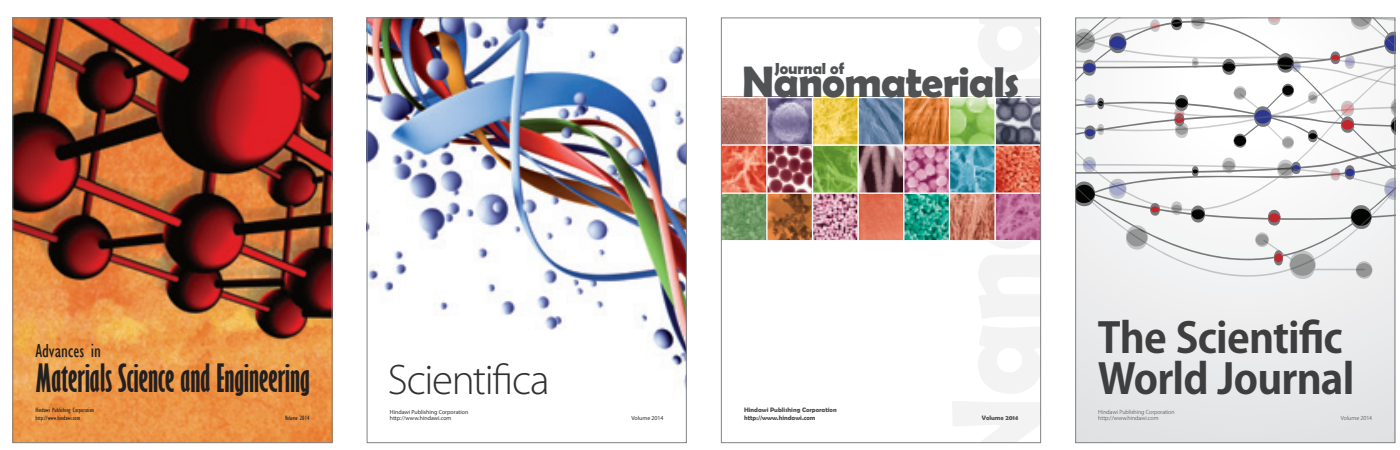

\section{The Scientific World Journal}
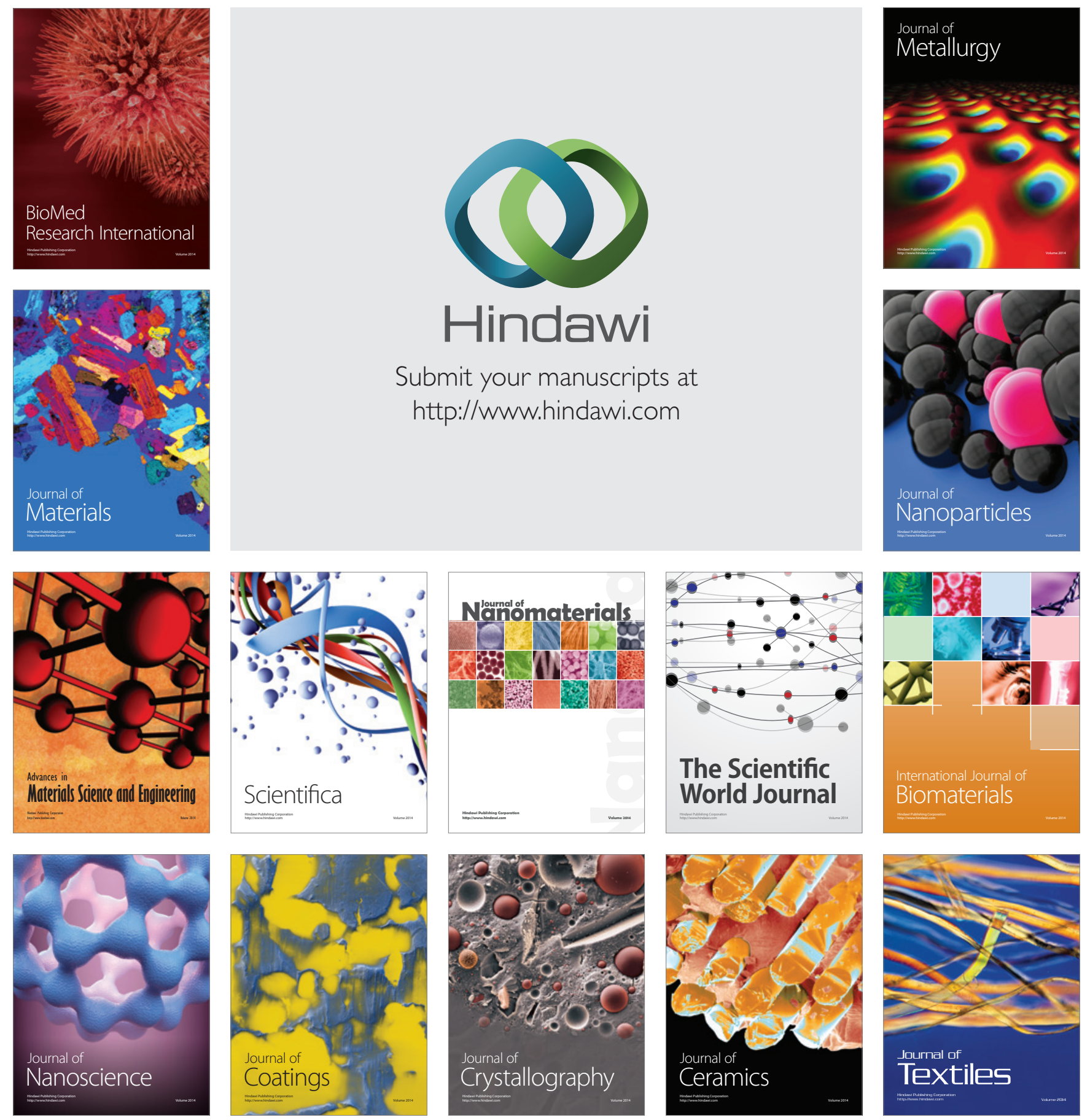